\title{
Compatibilidade de Dicyma pulvinata com defensivos agrícolas e eficiência do biocontrole do mal-das-folhas da seringueira em campo
}

\author{
Débora Ferreira Melo(1), Sueli Corrêa Marques de Mello(2), Carlos Raimundo Reis Mattos ${ }^{(3)}$ \\ e Saulo Emilio Almeida Cardoso(3)
}

\begin{abstract}
(1)Universidade de Brasília, Departamento de Fitopatologia, Caixa Postal 4457, CEP 70910-900 Brasília, DF. E-mail: deboramelo@pop.com.br (2)Embrapa Recursos Genéticos e Biotecnologia, Caixa Postal 02372, CEP 70770-900 Brasília, DF. E-mail: smello@cenargen.embrapa.br (3)Plantações Michelin da Bahia Ltda., Caixa Postal 02, CEP 45435-000 Ituberá, BA. E-mail: carlos.mattos@br.michelin.com, saulo.cardoso@br.michelin.com
\end{abstract}

Resumo - O objetivo deste trabalho foi avaliar quatro isolados do fungo antagonista Dicyma pulvinata quanto à compatibilidade com defensivos agrícolas e adjuvantes, e a eficiência desses isolados no controle do mal-das-folhas (Microcyclus ulei) da seringueira (Hevea sp.) em campo. A compatibilidade dos isolados com defensivos e adjuvantes foi avaliada com base no crescimento micelial e na esporulação do fungo, em testes conduzidos in vitro. Para avaliação da eficiência do antagonista contra $M$. ulei, em campo, os quatros isolados do antagonista foram comparados ao controle exercido pelo tratamento com os fungicidas propiconazol + mancozeb. Os ensaios conduzidos em laboratório indicaram a incompatibilidade de $D$. pulvinata com os fungicidas benomyl, carbendazim, mancozeb, propiconazol e, ainda, com o inseticida acaricida endosulfan. Dois dos adjuvantes testados (Tween 20 e Tween 80) não afetaram o desenvolvimento do fungo. Foi comprovada a ação do antagonista $D$. pulvinata sobre M. ulei, em campo, com destaque para os isolados CEN 62 e CEN 93, que apresentaram eficiência de controle semelhante ao tratamento fungicida padrão.

Termos para indexação: Microcyclus ulei, Hevea, controle biológico, controle químico.

\section{Compatibility of Dicyma pulvinata with pesticides and biocontrol efficiency of South American leaf blight of rubber tree under field conditions}

\begin{abstract}
The objective of this work was to evaluate four isolates of the antagonist fungus Dicyma pulvinata in terms of its compatibility with chemical pesticides and adjuvants products, and the efficiency of these isolates as biocontrol agent against South American leaf blight (Microcyclus ulei) of rubber tree (Hevea sp.) under field conditions. Isolates compatibility with chemical pesticides and adjuvants was evaluated on mycelial growth and fungus sporulation in vitro. To assess the efficiency of the antagonist against $M$. ulei under field conditions, the four isolates were compared to the control by the fungicide mixture propiconazol + mancozeb. The assays showed incompatibility of the antagonistic fungus with the fungicides benomyl, carbendazim, mancozeb, propiconazol, besides the insecticide-acaricide endosulfan. Two of the adjuvants tested did not affect the fungus development. It was demonstrated the action of D. pulvinata against $M$. ulei, in the field, especially for the isolates CEN 62 and CEN 93, which showed control levels similar to the fungicide standard treatment.
\end{abstract}

Index terms: Microcyclus ulei, Hevea, biological control, chemical control.

\section{Introdução}

A borracha natural produzida pela seringueira (Hevea spp.), particularmente pela espécie H. brasiliensis (Willd. ex Adr. de Juss.) Muell. Arg., é de grande importância na economia mundial, além de contribuir para a conservação do solo e melhoria do ambiente (Instituto de Pesquisas e Estudos Florestais, 2007). Entre as diversas doenças que atacam a cultura destaca-se o mal-das-folhas, causado pelo fungo
Microcyclus ulei (Henn.) Arx, que, no século passado, impediu o estabelecimento de seringais na Amazônia e é responsável pela fraca expansão da heveicultura no Brasil. Essa doença, além de reduzir a produção de látex, debilita as plantas e as leva à morte após desfolhamentos sucessivos (Gasparotto \& Ferreira, 1989).

O fungo M. ulei possui elevada capacidade de mutação (Mattos et al., 2003), o que lhe permite adaptar-se a diferentes condições climáticas (Gasparotto \& Junqueira, 1994). Esse fato poderá torná-lo grande 
problema também nas áreas de cultivo recentes (zonas de escape), para as quais a cultura se expandiu em virtude das condições de temperatura e umidade desfavoráveis ao desenvolvimento da doença (Tavares et al., 2004).

Após a constatação de que o fungo Dicyma pulvinata (Berk. \& M.A. Curtis) Arx [syn. Hansfordia pulvinata (Berk. \& M.A. Curtis) S. Hughes] coloniza estromas do M. ulei e destrói tanto os ascostromas como as estruturas anamórficas do patógeno (Fusicladium macrosporum J. Kuÿper), levantou-se a possibilidade de controlar biologicamente a doença, pelo uso desse micoparasita (Mello et al., 2006).

Junqueira \& Gasparotto (1991) mencionam que o controle do mal-das-folhas, com o micoparasita D. pulvinata, se associado a outros métodos de controle, como resistência genética e práticas de controle cultural, poderá ter muito valor prático nas regiões úmidas e quentes como o Estado do Amazonas e o sul do Estado da Bahia. De acordo com esses autores, a presença do M. ulei teria permitido a multiplicação de $D$. pulvinata e reduzido a densidade do patógeno na área de plantio, em experimento realizado em seringal da Embrapa Amazônia Ocidental, em Manaus, AM. Acrescente-se a isso que nas áreas de escape, em que o patógeno é problema particularmente sério em viveiros, $D$. pulvinata pode ser usado como um dos componentes do manejo sanitário das mudas. Nesses locais, onde a alta incidência da doença tem determinado a redução do crescimento e diminuição da percentagem de plantas para serem enxertadas (Romero et al., 2006), a aplicação do agente de biocontrole é facilitada pela baixa estatura das plantas.

O controle biológico de patógenos foliares pode apresentar baixa eficiência em campo, geralmente, em razão da falta de um bom veiculante de inóculo, da inadequação de tecnologias de aplicação ou, ainda, do impacto causado pelo ambiente. A obtenção de formulação adequada é um importante fator para o sucesso dos agentes de biocontrole, quando submetidos a variações ambientais (Fravel et al., 1998). Embora uma gama de agentes de biocontrole esteja disponível, a adoção efetiva dessa tecnologia requer melhor entendimento das interações presentes na natureza.

Durante a seleção de microrganismos antagônicos a fitopatógenos, os ensaios in vitro, muitas vezes necessários para estudos específicos, são insuficientes para se determinar o comportamento do antagonista in vivo. Desse modo, os ensaios de campo são fundamentais, visto que a ação antagonística depende de diversos fatores bióticos e abióticos (Bettiol, 1991).

A adição de adjuvantes ao inóculo é um recurso capaz de auxiliar o agente de biocontrole na superação de condições adversas e possibilitar a colonização do hospedeiro de maneira mais rápida e eficiente. Sob esse aspecto, considera-se importante encontrar aditivos que não causem efeitos tóxicos ao agente de biocontrole e que promovam melhorias em uma ou mais características essenciais, para o estabelecimento da interação antagonista (Fravel et al., 1998).

$\mathrm{O}$ uso combinado de agentes de controle biológico com pesticidas químicos, para obter efeitos sinergísticos ou aditivos contra o organismo alvo, é outra linha de estudo que tem despertado atenção. Doses reduzidas de fungicidas podem estressar e enfraquecer o patógeno e tornar seus propágulos mais suscetíveis ao ataque subseqüente pelo antagonista (Spadaro \& Gullino, 2005).

Este trabalho teve como objetivo avaliar quatro isolados do antagonista D. pulvinata, quanto à compatibilidade com defensivos agrícolas e adjuvantes, e quanto à eficiência no controle de M. ulei em campo.

\section{Material e Métodos}

Foram utilizados os isolados CEN 58, CEN 62, CEN 91 e CEN 93 de D. pulvinata, procedentes de Ouro Preto, RO, Belém, PA, Ituberá, BA e Ponte de Lacerda, MT, respectivamente. Esses isolados fazem parte da Coleção de Fungos para Controle Biológico, da Embrapa Recursos Genéticos e Biotecnologia (Cenargen).

Os ensaios para avaliação do efeito de defensivos e adjuvantes no crescimento e esporulação de D. pulvinata, bem como a produção de inóculo para uso no campo, foram desenvolvidos no Laboratório de Fitopatologia, do Núcleo Temático de Controle Biológico do Cenargen. Exceto em casos especificados, as colônias foram incubadas a $25^{\circ} \mathrm{C}$, com fotoperíodo de 12 horas. $\mathrm{O}$ fotoperíodo foi simulado por meio de quatro lâmpadas fluorescentes de $20 \mathrm{~W}$, à luz do dia, instaladas na porta da câmara de crescimento (Nova Técnica, modelo NT 708 - AT), onde as culturas foram mantidas em placas de Petri.

O experimento de campo foi conduzido de maio a novembro de 2005, em jardim clonal das Plantações Michelin Ltda., no Município de Ituberá, no litoral sul da Bahia, onde a incidência do mal-das-folhas vem ocorrendo com elevada severidade, ao longo dos anos. 
$\mathrm{Na}$ avaliação de efeitos de defensivos agrícolas no crescimento e esporulação dos isolados de D. pulvinata, os tratamentos foram compostos pelos fungicidas benomyl, carbendazim, propiconazol; pelo fungicida e acaricida mancozeb (representado por dois produtos comerciais diferentes), e pelos inseticidas e acaricidas malathion e endosulfan. Esses produtos foram utilizados nas doses equivalentes a um terço das concentrações recomendadas, pois em testes prévios notou-se a inibição total de crescimento do agente de biocontrole, quando foi adicionada a dose recomendada do produto. Baixas doses de fungicidas (e de inseticidas, em menor grau) podem funcionar como fator de estresse e, dessa forma, tornar o patógeno mais vulnerável ao antagonista (Spadaro \& Gullino, 2005). Cada produto foi adicionado em frascos individuais, com meio à base de batatadextrose-ágar (BDA), devidamente esterilizados e resfriados a $40^{\circ} \mathrm{C}$. O meio de cada frasco foi, então, vertido em placas de Petri. Como testemunhas, foram preparadas placas com meio BDA sem defensivos.

Cada placa recebeu um disco de $9 \mathrm{~mm}$ de colônias do fungo, com dez dias de idade, crescidas em BDA. Aos 16 dias de cultivo, avaliou-se o crescimento do fungo por meio de medidas do diâmetro das colônias e, aos 17 dias, por meio da esporulação. A contagem de esporos foi realizada com o auxílio de uma câmara de Neubauer, em alíquotas de suspensões obtidas pela adição de $10 \mathrm{~mL}$ de solução de Tween 80 (0,02\%), em cada placa, e raspagem das colônias com a alça de Drigalski.

Realizou-se a análise de variância para delineamento inteiramente casualizado em esquema fatorial (isolados $\mathrm{x}$ defensivos). As médias foram comparadas pelo teste de Tukey, a 5\% de probabilidade.

Para avaliação do efeito de adjuvantes sobre o desenvolvimento de colônias dos isolados de D. pulvinata, utilizaram-se oito produtos que, à exceção de sacarose, são de uso corrente na agricultura: Agral [nonil fenoxi poli (etilenoxi) etanol], Assit (óleo mineral parafínico), Extravon (aquil-fenol poliglicoleter), Iharaguen's (polioxieltileno alquifenol éter), óleo Natur'l (ésteres de ácidos graxos com glicerol), Tween 80 (polioxietileno monolaurático), Tween 20 (polioxietileno monolaurático) e sacarose. Placas de Petri com meio BDA receberam, cada uma, um disco com $9 \mathrm{~mm}$ de colônias do fungo, desenvolvidas nas mesmas condições descritas anteriormente. Esses discos foram previamente mergulhados, por 24 horas, em soluções preparadas com $20 \mathrm{~mL}$ de água destilada estéril, com os respectivos adjuvantes nas dosagens recomendadas.

Prepararam-se, também, dois tratamentos testemunha: um, cujos discos de cultura foram mergulhados em água destilada durante 24 horas e, então, transferidos para placas com BDA, e outro, cujos discos foram transferidos diretamente para as placas, sem qualquer tratamento. A incubação e avaliação foram realizadas da mesma forma que no experimento com os defensivos.

Para avaliação da eficiência dos isolados de D. pulvinata no biocontrole do mal-das-folhas em campo, o experimento foi conduzido em jardim clonal, com delineamento experimental de blocos ao acaso, em esquema fatorial $6 \times 4$, em que o fator a foi representado pelos tratamentos (isolados do fungo, fungicida e testemunha) e o fator b por clones de $\mathrm{H}$. brasiliensis, com quatro repetições. Os tratamentos (fator a) foram os seguintes: pulverização de suspensões ajustadas à concentração de $3.10^{5}$ esporos $\mathrm{mL}^{-1}$, preparadas com os isolados CEN 91, CEN 93, CEN 58 e CEN 62 de D. pulvinata (tratamentos 1 a 4, respectivamente); pulverização da mistura dos fungicidas propiconazol e mancozeb, nas concentrações de $3,5 \mathrm{~mL}$ e $2,5 \mathrm{~g}$, respectivamente, do ingrediente ativo por litro de água, acrescida de $5 \mathrm{~mL} \mathrm{~L}^{-1}$ de óleo Natur'l (tratamento 5); e testemunha (tratamento 6). As parcelas do tratamento testemunha receberam pulverização com água.

O fator b foi constituído pelos clones IRCA 41, IRCA 109, IRCA 111 e IRCA 230, com cerca de três anos de idade, todos altamente suscetíveis a M. ulei (Mattos et al., 2003) e plantados lado a lado, sob as mesmas condições de solo e clima.

As parcelas constituíram-se de cinco a sete fileiras de $14 \mathrm{~m}$, com sete plantas por fileira, em média. A área útil da parcela foi composta pelas duas fileiras centrais, e as demais foram consideradas bordaduras.

Para a preparação dos tratamentos com o agente de biocontrole usado no campo, inicialmente, cultivaram-se os isolados em erlenmeyers de $125 \mathrm{~mL}$, com $75 \mathrm{~mL}$ de meio líquido SDY (peptona, $10 \mathrm{~g} \mathrm{~L}^{-1}$; dextrose, $40 \mathrm{~g} \mathrm{~L}^{-1}$; extrato de levedura, $10 \mathrm{~g} \mathrm{~L}^{-1}$ ). Cada frasco recebeu cinco discos de colônias, obtidas como descrito nos experimentos anteriores, e foi mantido sob agitação em agitador orbital $(150 \mathrm{rpm})$ a $25^{\circ} \mathrm{C}$, durante sete dias. O micélio produzido $(20 \mathrm{~mL})$ foi transferido para sacos de plástico autoclavavéis $(42 \mathrm{~cm}$ de comprimento e $28 \mathrm{~cm}$ de largura), com o substrato sólido (200 g de arroz 
parboilizado, previamente umedecido com $120 \mathrm{~mL}$ de água destilada e autoclavado a $120^{\circ} \mathrm{C}$, durante $20 \mathrm{~min}$ ). $\mathrm{O}$ cultivo ocorreu em sala de incubação adaptada para tal fim, onde a temperatura se manteve a $25^{\circ} \mathrm{C}$, com fotoperíodo de 12 horas alternadas em claro/escuro. Após 17 dias de crescimento, os sacos foram abertos, e o fungo foi submetido à secagem em BOD a $28^{\circ} \mathrm{C}$ por três dias.

O fungo foi extraído do substrato por meio de duas lavagens com solução de Tween 80 a $0,02 \%$, seguidas de filtração. A suspensão, depois de ajustada à concentração de $3 \times 10^{5}$ esporos $\mathrm{mL}^{-1}$, foi aspergida sobre a superfície foliar das plantas, com pulverizador costal pressurizado com $\mathrm{CO}_{2}$, ao volume de calda de $0,13 \mathrm{~L}$ por planta. Foram realizadas seis aplicações quinzenais, sempre ao entardecer.

As avaliações se iniciaram 45 dias após a primeira aplicação dos tratamentos e foram repetidas duas vezes, em intervalos de 45 dias, em todas as plantas que apresentaram lançamentos com folhas no estádio $\mathrm{C}$ ou CD (Hallé et al., 1978). Para determinação da severidade da doença, utilizou-se a escala diagramática modificada (Mattos et al., 2003), baseada na área foliar lesionada, com exame de nove folíolos por planta. Avaliaram-se dez plantas ao acaso, por tratamento, em cada bloco. Os dados obtidos foram utilizados para cálculo da área abaixo da curva de progresso da doença (AACPD), representada pela soma da área dos polígonos para cada avaliação, tendo-se considerado o tempo (dias) como variável independente, e a severidade (\%) como variável dependente (Shaner \& Finney, 1977).

A presença de D. pulvinata sobre as lesões de M. ulei foi observada com o auxílio de lupa manual, com aumento de dez vezes. Para a confirmação do agente de biocontrole, foram coletados e examinados ao microscópio quatro folíolos de cada tratamento, tendose determinado a percentagem de estromas de $M$. ulei colonizados pelo hiperparasita. Três avaliações foram realizadas a intervalos de 45 dias.

Foi realizada a análise de variância de cada uma das variáveis e suas interações, para verificar o efeito dos tratamentos e clones. As médias foram comparadas pelo teste de Tukey, a 5\% de probabilidade.

\section{Resultados e Discussão}

$\mathrm{Na}$ avaliação dos efeitos de defensivos agrícolas sobre o desenvolvimento de $D$. pulvinata, observou-se inibição do crescimento de colônias com os produtos utilizados, em todos os isolados. Entretanto, no caso do malathion, a inibição foi parcial, ou seja, ele permitiu o desenvolvimento das colônias, embora, para todos os isolados esse desenvolvimento tenha sido significativamente inferior ao obtido na testemunha. Nas observações realizadas aos 16 dias de incubação das culturas, o isolado CEN 58 apresentou maior valor médio de diâmetro das colônias em presença do malathion, enquanto os demais isolados não diferiram significativamente entre si. Não houve interação entre tratamentos e isolados e, assim, são apresentadas as médias gerais para todos os isolados (Figura $1 \mathrm{~A}$ ).

A esporulação de D. pulvinata foi constatada, na avaliação realizada aos 17 dias de incubação, tanto nas placas testemunha quanto naquelas com malathion (Figura 1 B). A interação foi significativa para inseticida $\mathrm{x}$ isolado. $\mathrm{O}$ valor médio de produção de esporos na testemunha não diferiu dos observados nos tratamentos com inseticida, para os isolados CEN 62 e CEN 93, que também não diferiram entre si. Para o isolado CEN 91, detectou-se diferença significativa entre os tratamentos testemunha (que teve maior produção de esporos) e inseticida. Neste tratamento, o CEN 91 não diferiu dos dois isolados anteriores, ao passo que no tratamento testemunha ele diferiu de todos os isolados. Para o isolado CEN 58, a diferença foi significativa não só entre os tratamentos testemunha e inseticida, mas também em comparação aos isolados CEN 62 e CEN 93, quando em presença do inseticida. $\mathrm{Na}$ ausência do inseticida, o CEN 58 apresentou a média mais elevada de produção de esporos e, também, diferiu de todos os outros isolados.

Spadaro \& Gullino (2005) preconizam a possibilidade de combinação de controle químico e biológico, por meio de aplicações de doses relativamente baixas dos produtos químicos, com o propósito de estressar o patógeno e torná-lo vulnerável aos microrganismos antagônicos. Resultados favoráveis na implementação dessa estratégia foram obtidos com o biofungicida AQ10 (Ampelomyces quisqualis), usado no biocontrole de Podosphaera xanthii, que mostrou ser compatível com os fungicidas myclobutanil e triadimeton, em estudos realizados por Shishkoff \& McGrath (2002), nas concentrações de $10 \mu \mathrm{g} \mathrm{mL}^{-1} \mathrm{e}$ $100 \mu \mathrm{g} \mathrm{mL}^{-1}$, respectivamente. Ainda, a substituição de alguns dos tratamentos químicos pelo agente biológico (alternância de tratamentos) além de reduzir a quantidade de químicos liberada no ambiente, resultaria 
em controle mais efetivo da doença. Os resultados obtidos neste trabalho indicaram, no entanto, que há incompatibilidade entre $D$. pulvinata e os fungicidas avaliados, mesmo em baixas concentrações.

Os inseticidas endosulfan e malathion também exerceram efeitos negativos sobre o desenvolvimento do fungo in vitro, o que indica que também no tocante ao uso de inseticidas químicos, para controle de eventuais pragas, deverão ser buscadas formas de utilização que minimizem os efeitos tóxicos ao fungo antagonista.

Com relação ao uso de adjuvantes, os resultados obtidos mostraram que não houve efeito de nenhum desses produtos no crescimento micelial dos isolados. Quanto à esporulação, entretanto, observou-se
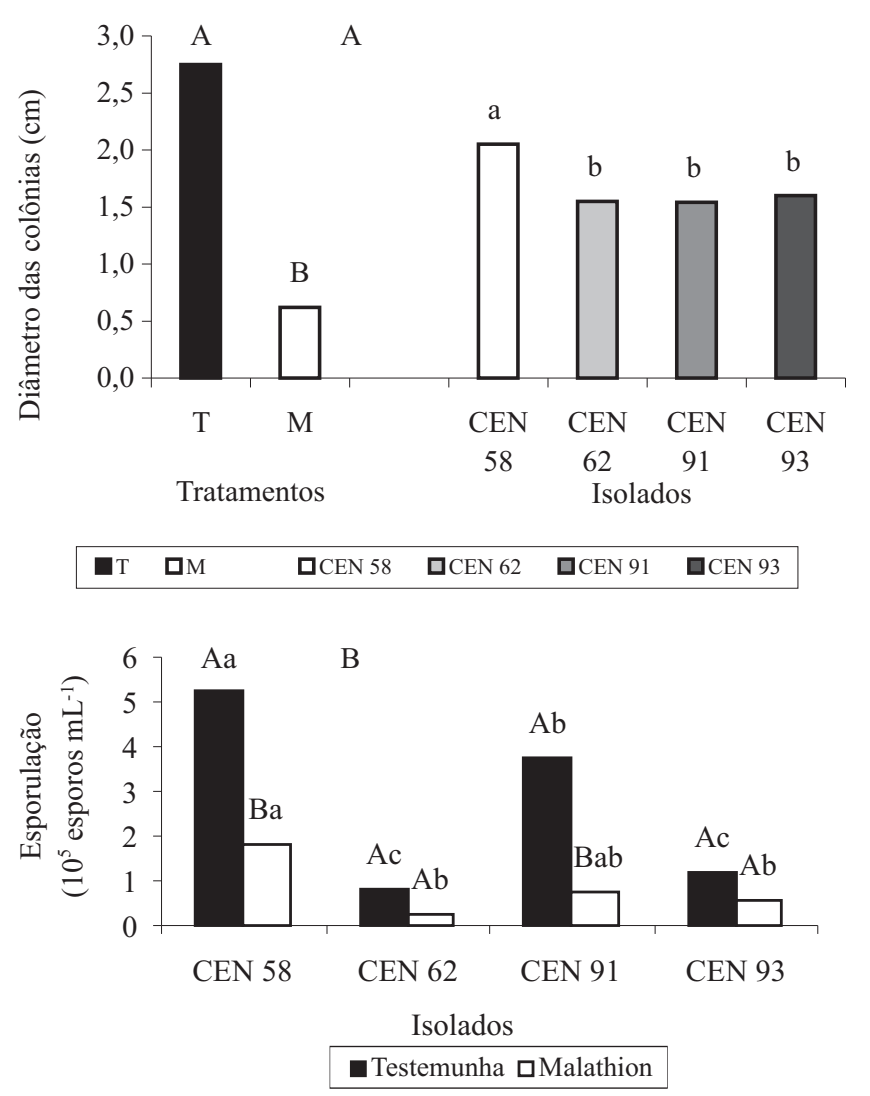

Figura 1. Desenvolvimento de Dicyma pulvinata em meio de cultivo BDA como testemunha (T), e meio acrescido de malathion (M). A: diâmetro médio de colônias aos 16 dias de cultivo; B: esporulação aos 17 dias de cultivo. Letras maiúsculas comparam os tratamentos com malathion e testemunha, em cada isolado, e letras minúsculas comparam as médias entre os isolados. interação entre os fatores (adjuvante x isolado). Não foram detectadas diferenças significativas entre tratamentos, com os isolados CEN 91 e CEN 93. Com os isolados CEN 58 e CEN 62, houve diferença significativa não só entre tratamentos, em alguns casos, mas também maior variedade de resposta, quando comparados entre si e aos outros dois isolados (Tabela 1).

A despeito da reconhecida importância do desenvolvimento de formulações, para o sucesso de agentes de biocontrole de fitopatógenos (Mitchell \& Taber, 1986; Burges, 1998; Fravel et al., 1998; Greaves et al., 1998; Oshiman, 2000; Shishkoff \& McGrath, 2002), há relativamente poucos estudos que demonstram os benefícios de adjuvantes ou substâncias carreadoras de propágulos fúngicos. No caso específico de D. pulvinata, Mitchell \& Taber (1986) relataram maior colonização de lesões de Cercosporidium personatum por um isolado desse antagonista, quando os esporos foram suspensos em Tween 80 e glicerol, ambos em diversas concentrações, e CMC (metilcelulose) nas concentrações de 0,4 e $0,8 \%$.

Neste trabalho, os sufactantes Tween 20 e Tween 80 , nas concentrações utilizadas, não afetaram a esporulação de nenhum dos quatro isolados de $D$. pulvinata e poderão contribuir para uma melhor ação do agente de biocontrole em campo. Ambos os produtos podem servir como emulsificadores, dispersantes e estabilizadores e,

Tabela 1. Produção de esporos (x10 esporos $\left.\mathrm{mL}^{-1}\right)$ em meio BDA, em colônias de quatro isolados de Dicyma pulvinata, desenvolvidas a partir de discos de micélio tratados com diferentes adjuvantes ${ }^{(1)}$.

\begin{tabular}{lllll}
\hline \multirow{2}{*}{ Tratamento } & \multicolumn{4}{c}{ Isolados } \\
\cline { 2 - 5 } & \multicolumn{1}{c}{ CEN 58 } & \multicolumn{1}{c}{ CEN 62 } & CEN 91 & CEN 93 \\
\hline Agral & $1,38 \mathrm{BCa}$ & $1,05 \mathrm{ABab}$ & $1,23 \mathrm{Aab}$ & $0,85 \mathrm{Aa}$ \\
Assist & $1,24 \mathrm{BCa}$ & $0,89 \mathrm{Ba}$ & $1,22 \mathrm{Aa}$ & $0,92 \mathrm{Aa}$ \\
Extravon & $1,31 \mathrm{BCa}$ & $0,91 \mathrm{Bb}$ & $0,84 \mathrm{Ab}$ & $0,90 \mathrm{Ab}$ \\
Iharanguen's & $1,13 \mathrm{Ca}$ & $1,14 \mathrm{ABa}$ & $1,20 \mathrm{Aa}$ & $1,05 \mathrm{Aa}$ \\
Óleo Natur'1 & $1,44 \mathrm{BCa}$ & $1,13 \mathrm{ABab}$ & $1,26 \mathrm{Aab}$ & $0,95 \mathrm{Ab}$ \\
Tween 80 & $1,93 \mathrm{Aa}$ & $1,19 \mathrm{ABb}$ & $1,03 \mathrm{Ab}$ & $0,92 \mathrm{Ab}$ \\
Tween 20 & $1,56 \mathrm{ABCa}$ & $0,99 \mathrm{ABb}$ & $1,16 \mathrm{Ab}$ & $1,05 \mathrm{Ab}$ \\
Sacarose & $1,34 \mathrm{BCa}$ & $1,10 \mathrm{ABab}$ & $0,91 \mathrm{Ab}$ & $0,94 \mathrm{Ab}$ \\
Água & $1,62 \mathrm{ABa}$ & $1,44 \mathrm{Aab}$ & $1,22 \mathrm{Abc}$ & $1,05 \mathrm{Ac}$ \\
Sem tratamento & $1,70 \mathrm{ABa}$ & $1,39 \mathrm{Aab}$ & $1,22 \mathrm{Ab}$ & $1,04 \mathrm{Ab}$ \\
\hline
\end{tabular}

(1)Médias seguidas por letras iguais, maiúsculas nas colunas e minúsculas nas linhas, não diferem entre si pelo teste de Tukey, a 5\% de probabilidade. 
por serem, em geral, menos tóxicos do que os sufactantes iônicos (Greaves et al., 1998), estão entre os mais comumente usados.

De acordo com Rocha \& Vasconcelos Filho (1978), o sudeste da Bahia é classificado como altamente favorável ao mal-das-folhas. Para Gasparotto et al. (1989), a temperatura e o período de molhamento foliar influenciam significativamente a infecção de folíolos de seringueira por M. ulei. Neste trabalho, verificou-se umidade relativa média de $97 \%$ e temperatura máxima de $26^{\circ} \mathrm{C}$ e mínima de $19,5^{\circ} \mathrm{C}$, nos dias de aplicação dos tratamentos em campo. Além disso, foi observada, durante todo o período de realização dos ensaios, alta pluviosidade na região.

A análise de variância dos valores de área abaixo da curva de progresso de doença, estimados a partir dos dados obtidos nas três épocas de avaliação de severidade do mal-das-folhas, nos experimentos de campo, mostrou que não houve efeito de clones, tampouco da interação entre clones e tratamentos. Contudo, houve efeito dos tratamentos aplicados (Figura 2).

Todos os isolados, em todos os clones estudados, propiciaram redução na área foliar lesionada. Os tratamentos com os isolados CEN 62, CEN 93 e com a mistura de fungicidas não diferiram estatisticamente entre si e foram os mais eficientes no controle da doença, com os menores valores médios de AACPD. Os isolados CEN 58 e CEN 91 apresentaram baixos valores médios de AACPD, se comparados à testemunha, embora com valores significativamente mais elevados em relação aos demais tratamentos (Figura $2 \mathrm{~A}$ ).

$\mathrm{Na}$ terceira avaliação, aos 135 dias, completados 45 dias da última aplicação, observou-se grande incremento dos níveis de severidade do mal-dasfolhas, em todas as parcelas tratadas, provavelmente em razão do fim do efeito residual dos tratamentos aplicados.

Quanto à percentagem de estromas colonizados por $D$. pulvinata, não houve interação significativa entre os fatores períodos de avaliação $(45,90 \mathrm{e}$ 135 dias após a aplicação) e isolados. Para todos os isolados testados, os maiores valores médios de percentagem de colonização de estromas de $M$. ulei pelo hiperparasita ocorreram aos 45 dias após a primeira aplicação. Entretanto, esses valores foram decrescentes nas avaliações posteriores (Figura 2 B).
Experimentos conduzidos em casa de vegetação por Mello et al. (2006), com 20 isolados de D. pulvinata, indicaram maior agressividade do isolado CEN 93 ao M. ulei. No presente trabalho, esse isolado apresentou eficiência semelhante aos demais testados sob condições de campo, em termos de colonização dos estromas do patógeno.

Sucesso parcial do controle biológico tem sido observado em avaliações conduzidas em campo com diversos agentes de controle biológico (Mitchell et al., 1986; Kupper et al., 2003; Shternshis et al., 2005).
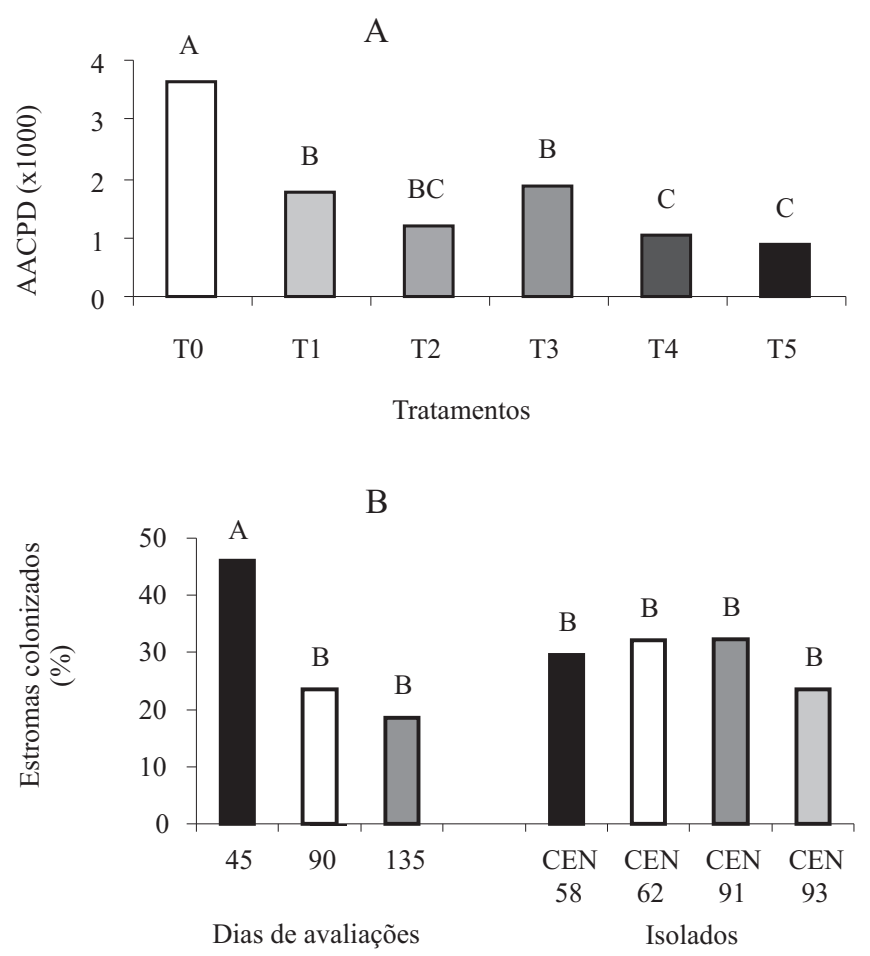

Figura 2. Severidade do mal-das-folhas da seringueira, em condições de campo. A: área abaixo da curva de progresso da doença (AACPD), considerando-se tempo (dias) como variável independente e percentagem da área foliar lesionada como variável dependente, em resposta aos tratamentos (T0, testemunha; T1, CEN 91; T2, CEN 93; T3, CEN 58; T4, CEN 62; T5, fungicida); B: percentagem de estromas de Microcyclus ulei colonizados por Dicyma pulvinata, em diferentes períodos de avaliação, em resposta à aplicação dos isolados. Barras com letras iguais não diferem entre si pelo teste de Tukey, a 5\% de probabilidade. 


\section{Conclusões}

1. O hiperparasita Dicyma pulvinata não é compatível com defensivos comumente utilizados nos seringais da região Sudeste da Bahia.

2. O crescimento micelial do hiperparasita não é afetado pela presença dos adjuvantes testados, porém a esporulação pode ser afetada.

3. Os isolados de D. pulvinata CEN 58, CEN 62, CEN 91 e CEN 93 são promissores para o controle biológico de mal-das-folhas no Sudeste da Bahia.

\section{Agradecimentos}

Ao Conselho Nacional de Desenvolvimento Científico e Tecnológico, pela concessão de bolsa.

\section{Referências}

BETTIOL, W. Seleção de microrganismos antagônicos a fitopatógenos. In: BETTIOL, W. (Org.). Controle biológico de doenças de plantas. Jaguariúna: Embrapa-CNPDA, 1991. p.225-236.

BURGES, H.D. Formulation of mycoinseticides. In: BURGES, H.D. (Ed.). Formulation of microbial biopesticides: beneficial microorganisms, nematodes and seed treatments. Dordrecht: Kluwer Academic Publishers, 1998. p.187-202.

FRAVEL, D.R.; CONNICK, W.J.; LEWIS, J.A. Formulation of microorganis to control plant diseases. In: BURGES, H.D. (Ed.). Formulation of microbial biopesticides: beneficial microorganisms, nematodes and seed treatments. Dordrecht: Kluwer Academic Publishers, 1998. p.187-202.

GASPAROTTO, L.; FERREIRA, F.A. Doenças da seringueira. In: FERREIRA, F.A. (Ed.). Patologia florestal: principais doenças florestais no Brasil. Viçosa: Sociedade de Investigações Florestais, 1989. p.290-313.

GASPAROTTO, L.; JUNQUEIRA, N.T.V. Ecophysiological variability of Microcyclus ulei, causal agent of rubber tree leaf blight. Fitopatologia Brasileira, v.18, p.22-28, 1994.

GASPAROTTO, L.; ZAMBOLIM, L.; MAFFIA, L.A.; VALE, F.X.R. do; JUNQUEIRA, N.T.V. Efeito da temperatura e umidade sobre a infecção de seringueira (Hevea spp.) por Microcyclus ulei. Fitopatologia Brasileira, v.14, p.38-41, 1989.

GREAVES, M.P.; HOLLOWAY, P.J.; AULD, B.A. Formulation of microbial herbicides. In: BURGES, H.D. (Ed.). Formulation of microbial biopesticides: beneficial microorganisms, nematodes and seed treatments. Dordrecht: Kluwer Academic Publishers, 1998. p.203-235.

HALLÉ, F.; OLDEMAN, R.A.; TOMLINSON, P.B. Tropical trees and forest. Berlin: Springer-Verlag, 1978. 441p.
INSTITUTO DE PESQUISAS E ESTUDOS FLORESTAIS. Hevea brasiliensis (seringueira). Disponível em: http:www.ipef.br/identificacao/hevea.brasiliensis.asp. Acesso em: 31 out. 2007.

JUNQUEIRA, N.T.V.; GASPAROTTO, L. Controle biológico de fungos estromáticos causadores de doenças foliares em seringueira. In: BETTIOL, W. (Org.). Controle biológico de doenças de plantas. Jaguariúna: Embrapa-CNPDA, 1991. p.307-331.

KUPPER, K.C.; GIMENES-FERNANDES, N.; GOES, A. Biological control of Colletotrichum acutatum, causal agent of citrus postbloom fruit drop disease. Fitopatologia Brasileira, v.28, p.251257, 2003.

MATTOS, C.R.R.; GARCIA, D.; PINARD, F.; LE GUEN, V. Variabilidade de isolados de Microcyclus ulei no Sudeste da Bahia. Fitopatologia Brasileira, v.28, p.502-507, 2003.

MELLO, S.C.M.; SANTOS, M.F.; SILVA, J.B.T. Isolados de Dicyma pulvinata em estromas de Microcyclus ulei em seringueira. Pesquisa Agropecuária Brasileira, v.41, p.359-363, 2006.

MITCHELL, J.K.; TABER, R.A. Factors affecting the biological control of Cercosporidium leaf spot of peanuts by Dicyma pulvinata. Phytopathology, v.76, p.990-994, 1986.

OSHIMAN, K. Sodium alginate as an adjuvant of an antagonistic bacterium, Pseudomonas fluorescens strain A11RN, to enhance biocontrol of turfgrass snow mold caused by Typhula ishikariensis. Journal of Genetics and Plant Pathology, v.66, p.258-263, 2000.

ROCHA, H.M.; VASCONCELOS FILHO, A.P. Epidemiology of the South American leaf blight of rubber in the region of Ituberá, Bahia, Brazil. Turrialba, v.28, p.325-329, 1978.

ROMERO, I.A.G.; ARISTIZÁBAR, F.A.; CASTAÑO, D.M. Revisión sobre el hongo Microcyclus ulei, agente causal del mal de la hoja del caucho. Revista Colombiana de Biotecnología, v.8, p.5059, 2006.

SHANER, G.; FINNEY, R.E. The effect of of nitrogen fertilization on the expression of slow-mildewing resistance in Knox wheat. Phytopathology, v.67, p.1051-1056, 1977.

SHISHKOFF, N.; MCGRATH, M.T. AQ10 biofungicide combined with chemical fungicides or AddQ spray adjuvant. Plant Disease, v.86, p.915-918, 2002.

SHTERNSHIS, M.; TOMILOVA, O.; SHPATOVA, T.; SOYTONG, $\mathrm{K}$. Evaluation of ketomium-mycofungicide on siberian isolates of phytopathogenic fungi. Journal of Agricultural Technology, v.1, p.247-253, 2005.

SPADARO D.; GULLINO, M.L. Improving the efficacy of biocontrol agents against soilborne pathogens. Crop Protection, v.24, p.601-613, 2005.

TAVARES, E.T.; TIGANO, M.S.; MELLO, S.C.M.; MARTINS, I.; CORDEIRO, D.M.T. Molecular characterization of Brazilian Dicyma pulvinata isolates. Fitopatologia Brasileira, v.29, p.148-154, 2004.

$\overline{\text { Recebido em } 28 \text { de agosto de } 2007 \text { e aprovado em } 21 \text { de janeiro de } 2008}$ 